\title{
Mechanism and Stability of a Redox Supercapacitor based on Methylene Blue: Effects of Degradation of the Redox Shuttle
}

Paulo F. R. Ortega ${ }^{\mathrm{a}, \mathrm{b}}$, Fabiano G. F. de Paula ${ }^{\mathrm{a}}$, Mateus C. M. de Castro ${ }^{\mathrm{a}}$, Ildefonso Binatti $^{\mathrm{b}}$, Zoraida González ${ }^{\mathrm{c}}$, Clara Blanco ${ }^{\mathrm{c}}$, Ricardo Santamaría ${ }^{\mathrm{c} *}$, and Rodrigo L. Lavall $^{\mathrm{a} *}$

a. Departamento de Química/ICEx - Universidade Federal de Minas Gerais. Av. Antônio Carlos, 6627 - Pampulha, CEP 31270-901, Belo Horizonte - MG, Brazil

b. Centro Federal de Educação Tecnológica de Minas Gerais - Campus IV. Av. Ministro Olavo Drummond, 25 - São Geraldo, CEP 38180-510, Araxá - MG, Brazil

c. Instituto Nacional del Carbón, INCAR-CSIC, Apdo. 73, 33080-Oviedo, Spain

*Corresponding authors. E-mail: rodrigo.lavall@qui.ufmg.br (R.L.Lavall) and riqui@incar.csic.es (R. Santamaría). 


\begin{abstract}
The mechanism of operation of a supercapacitor based on methylene blue (MB) as redox shuttle in cells containing activated carbon as electrodes and aqueous electrolyte has been studied. Attention is focused on the instability of these molecules which can undergo secondary reactions that impact negatively on the cell, generating fluctuations in its performance and reducing its cycling life. It is demonstrated that $\mathrm{MB}$ interacts strongly with activated carbons and modifies their structure, decreasing the resistance of the electrodes and increasing the energy density of the cell by more than $40 \%$. It is also shown that MB is not stable in acidic electrolyte at the high potentials attained by the electrodes of the supercapacitor. Demethylation byproducts and oxidized derivates of the $\mathrm{MB}$ were detected after cycling by means of electrospray ionization mass spectrometry. These products were observed to cause a constant change in the equilibrium potential of the cell, substantially modifying the storage mechanism and the ranges of operation potential of the electrodes.
\end{abstract}

Keywords: supercapacitor, redox shuttle, methylene blue, degradation, cycling stability 


\section{Introduction}

Supercapacitors (SCs) are energy storage devices that have been the focus of numerous studies in recent years due to their applicability in electric and hybrid vehicles. ${ }^{1-2}$ The first generation of these devices, also known as electrochemical doublelayer capacitors (EDLC), was based on high-surface-area-carbon materials (most commonly activated carbons) as electrodes that are able to accumulate charge mainly due the formation of the electric double layer at the electrode/electrolyte interface. ${ }^{3}$ In this mechanism, the SCs attained capacitances up to a hundred times greater than conventional capacitors (electrostatic and electrolytic) but their energy density did not reach parity with that attainable by batteries, especially with those of the ion-lithium type. However, SCs are able to withstand a high number of cycles $\left(>10^{4}\right)$ and to operate at higher power densities than batteries which make them more suitable in applications where short-term power pulses are required. ${ }^{3}$

Over the last decade, great effort has been made to surpass the limits of current SC technology, especially in terms of energy density. It is expected that a second generation of SCs will be able to satisfy the ever increasing energy and power demands. ${ }^{4-6}$ Different approaches have been used to construct the new generation of SCs that combines the storage mechanisms of batteries and EDLC. One such approach has resulted in composite electrodes containing electrochemically active precursors combined with high-surface-area materials. ${ }^{5,7}$ In another, one of the carbon electrodes is replaced by one electrode of the battery type, such as metal oxide, phosphates, graphite. ${ }^{5-9}$ In this case, the systems are referred to as hybrid SCs or supercapatteries, all of which can reach energy densities ten times that attainable by EDLCs.

In 2010, Roldán et al. developed a new way to increase the energy of SCs by simply modifying the electrolyte through the dissolution of active redox species. ${ }^{10}$ In these cells, both electrodes were composed of carbon and operated through a double layer mechanism, while at the same time the active compound dissolved in the electrolyte underwent reversible redox processes at the carbon interface. With this method, the researchers managed to surpass the energy density of conventional SCs, thereby lowering the cost, without any significant loss of power density while maintaining a reasonable cycling performance. Their success gave rise to many other studies in which various redox compounds (both organic and inorganic), with different cell configurations were tested. ${ }^{11-14}$ 
In the case of SCs containing redox shuttles (abbreviated here to redox-SC), the choice of components must take into account the mechanisms involved in the accumulation of charge. It is essential that the carbon materials have excellent physicochemical properties in order to ensure a good charge accumulation through the electric double layer, and that there is no restriction to the transfer of electrons to the redox compounds. ${ }^{15}$ First and foremost, therefore, the carbon materials must have a high surface area and very high electrical conductivity. However, these two properties are often not found together in the conventional carbon compounds employed in SCs. Carbon nanotubes, graphite compounds and some fibers are classes of materials that have a very high electrical conductivity and are highly suitable to be used with redox additives, but they have low surface area values. ${ }^{15-16}$ In contrast, activated carbon (ACs) are carbon materials with a very high specific surface area, making them the materials most commonly used in commercial SCs. ${ }^{16-17}$ However, their disorganized structure, with its large number of functional groups and defects, restricts their electrical conductivity and impedes the reversibility essential to the redox processes. For this reason, some researches have turned their attention to building asymmetric SCs that contains a capacitive carbon electrode with a high surface area and a second carbon electrode with a small area, but with a good conductivity, in order to guarantee the reaction of the additive inserted into the electrolyte. ${ }^{18}$

Some redox compounds are easily adsorbed by the ACs and, despite the relatively low electrical conductivity, molecules such as methylene blue, viologens and some halides undergo reversible oxi-reduction processes at the interface of these materials, while their cells also exhibit a low self-discharge. ${ }^{13}$ This shows that these redox additives are not only easily adsorbed at the interface of the AC but probably interact and "settle" into the 3D structure of the carbon. Methylene blue (MB), for example, has planar chemical structures that could interact by means of $\pi-\pi$ forces and insert itself between the lamellae of higher $\mathrm{sp}^{2}$ carbon content present in the AC. This possibility is supported by a recent work of Montes-Navajas et al., ${ }^{19}$ who used the adsorption of $\mathrm{MB}$ as a criterion for determining the specific surface area of graphene materials from the adsorption of MB monolayers, mainly retained by the $\pi-\pi$ interaction with graphene layers.

Despite the energy gains to be derived from the incorporation of the redox shuttles in SCs, it is important to bear in mind that their use introduces an element of complexity to the cells. Many of these additives are large reactive organic molecules 
that can seriously interfere with the performance and stability of the cells. Theoretically, structural changes in these molecules could modify the operating potential and the equilibrium potential of the cell, reduce its adsorption capacity, and affect its cycling. Each redox-SC therefore will be unique in its behavior and dependent in its chemical make-up.

For this work, we have chosen a redox-SC based on MB and studied not only the performance of the cell, but also the mechanism of degradation caused by the redox additive. MB was chosen because of its very rich chemistry that has been widely studied with several mechanisms being proposed depending on the media conditions (such as $\mathrm{pH}) .{ }^{20-21}$ It is also well-known that significant amounts of $\mathrm{MB}$ can be strongly adsorbed into the AC. ${ }^{22}$ Thus, SC cells have been assembled with ACs containing pre-adsorbed MB using an aqueous acid solution as electrolyte.

Initially, ACs synthesized at various temperatures were evaluated as redox-SC electrodes using cyclic voltammetry. The cell with the best $\mathrm{AC}$ was then subjected to a complete electrochemical characterization by chronopotentiometry with simultaneous recording of the potential of the electrodes and the voltage of the cell. Finally, the cyclability and degradation mechanism of MB in each electrode was studied by means of electrospray ionization mass spectrometry (ESI-MS).

\section{Experimental Section}

Preparation of the $\mathbf{A C}$ electrodes. The activated carbons used in this work $\left(\mathrm{AC}_{600}\right.$, $\mathrm{AC}_{700}$ and $\left.\mathrm{AC}_{800}\right)$ were obtained from polystyrene waste using three different activation temperatures $\left(600,700\right.$ and $800{ }^{\circ} \mathrm{C}$, respectively) ${ }^{23}$. Further details on the preparation of the carbons and their characterization are included in the Supporting Information. MB was pre-adsorbed on CA samples prior to the electrode preparation as described previously. ${ }^{23} \mathrm{MB}$ pre-adsorption was used to ensure greater accuracy in the calculations of specific electrochemical parameters (normally expressed per gram of active material in the electrodes), since it is not possible to determine the exact amount of additive that undergoes oxidation and reduction processes at the interface when it is dissolved in the electrolyte. The electrodes for the supercapacitors were prepared by mixing $90 \mathrm{wt} . \%$ of the corresponding $\mathrm{AC}$ (pure or containing pre-adsorbed $\mathrm{MB}$ ) and $10 \mathrm{wt} \%$ of polytetrafluoroethylene (PTFE) as binder. The mixture was prepared in a mortar and pressed into disk-shaped electrodes (weighing approximately $20 \mathrm{mg}$ each, with a diameter of $1.13 \mathrm{~cm}^{2}$ and a thickness of $0.4 \mathrm{~mm}$ ). 
Fabrication of supercapacitor cells and electrochemical characterization. SCs were prepared using a "T-type" Swagelok ${ }^{\circledR}$ cell with glass fiber separators between two carbon electrodes (pure or containing pre-adsorbed MB). An aqueous solution of $1.0 \mathrm{M}$ $\mathrm{H}_{2} \mathrm{SO}_{4}$ was used as electrolyte. To record the potentials of the electrodes, an $\mathrm{Ag} / \mathrm{AgCl} / 3.5 \mathrm{M} \mathrm{KCl}$ reference electrode was used as a third-end connection. All the electrochemical measurements were performed in a Biologic VMP Potentiostat/Galvanostat (USA) at room temperature. Synchronous cyclic chronopotenciometry, where the cell voltage and the potential of each electrode are recorded simultaneously, were performed at different current densities (0.05-1.0 A g $\left.{ }^{-1}\right)$. The equations used for calculations of the cell capacitance $\left(\mathrm{C}_{\text {cell }}\right)$, electrode capacitance $\left(\mathrm{C}_{+}, \mathrm{C}_{-}\right)$, energy density $(\mathrm{E})$, power density $(\mathrm{P})$, equivalent series resistance (ESR) and coulombic efficiency $(\varepsilon)$ can be found in the cited references. ${ }^{8}{ }^{14}$ In this work, the masses of active material used in the calculations correspond to the masses of AC containing pre-adsorbed MB.

Cyclic voltammetry tests, using a 3 electrode configuration, were conducted at scan rates of $1,3,5,7$ and $10 \mathrm{mV} \mathrm{s}^{-1}$ in a potential range of -0.20 to $0.55 \mathrm{~V}$, in which the carbon electrode (containing pre-adsorbed MB) is used as working electrode, Pt wire as the counter electrode and an $\mathrm{Ag} / \mathrm{AgCl} / 3.5 \mathrm{M} \mathrm{KCl}$ electrode as reference.

Electrochemical impedance spectroscopy (EIS) measurements were taken of to the global cells ( 2 electrode configuration) and of the individual electrodes ( 3 electrode configuration), in a frequency range from $1 \mathrm{MHz}$ to $0.05 \mathrm{~Hz}$ at the open circuit potential with an ac perturbation of $10 \mathrm{mV}$. EIS measurements were performed with the same assembly used in galvanostatic experiments.

Electronspray ionization mass spectrocospy. Electronspray ionization mass spectrocospy (ESI-MS) was employed to study the degradation of MB adsorbed on the electrodes after cell cycling. To extract the MB and its derivatives, equal portions of the electrodes (removed from the cells before and after the cycling experiments) were cut out and added to $1 \mathrm{~mL}$ of methanol. After $10 \mathrm{~min}$ of extraction at room temperature, 20 $\mu \mathrm{L}$ of the obtained solution was diluted in $980 \mu \mathrm{L}$ of methanol and subjected to analysis. Mass spectra were recorded by an electrospray ionization mass spectrometer and an ion trap analyzer (LCQ-Fleet, Thermo-Scientific). To obtain the spectra, the methanolic phase was continuously injected into the mass spectrometer. The sample 
was pumped in using a syringe (Hamilton $500 \mu \mathrm{L}$ ) at a flow rate of $30 \mu \mathrm{L} \min ^{-1}$. The voltage applied to the electrospray formation was $+5.0 \mathrm{kV}$ and for the positive mode, the desolvation temperature was $275^{\circ} \mathrm{C}$.

\section{Results and discussion}

Characterization of the carbon electrodes. The ACs used in this study present $S_{B E T}$ and $V_{\text {total }}$ values above $2100 \mathrm{mg} \mathrm{g}^{-1}$ and $0.85 \mathrm{~cm}^{3} \mathrm{~g}^{-1}$, respectively (Figure $\mathrm{S} 1$ and Table S1, see S.I.), therefore they are suitable for the used as active materials in EDLC electrodes, as demonstrated elsewhere. ${ }^{23}$ Furthermore, in the case of redox-SC, the chemical composition and conductivity of the materials become key factors because these properties impact on the reversibility of the faradaic reactions and in the amount of adsorbed redox shuttle. The increase in the activation temperature drastically reduced the resistivity of the $\mathrm{ACs}$, it ranging from $1094 \Omega \mathrm{cm}\left(\mathrm{AC}_{600}\right)$ to only $6 \Omega \mathrm{cm}\left(\mathrm{AC}_{800}\right){ }^{23}$ All this results in a significant variation in the amount of $\mathrm{MB}$ adsorbed, which increases from $270 \mathrm{mg} \mathrm{g}^{-1}$ for $\mathrm{AC}_{600}$, to $536 \mathrm{mg} \mathrm{g}^{-1}$ for $\mathrm{AC}_{700}$ and to $1042 \mathrm{mg} \mathrm{g}^{-1}$ for $\mathrm{AC}_{800}$.

Three electrodes cyclic voltammetry is the most suitable technique for studying the redox processes that occur in the electrodes. Figure 1 shows the cyclic voltammograms for the electrodes prepared with the three ACs containing adsorbed MB at different scan rates.

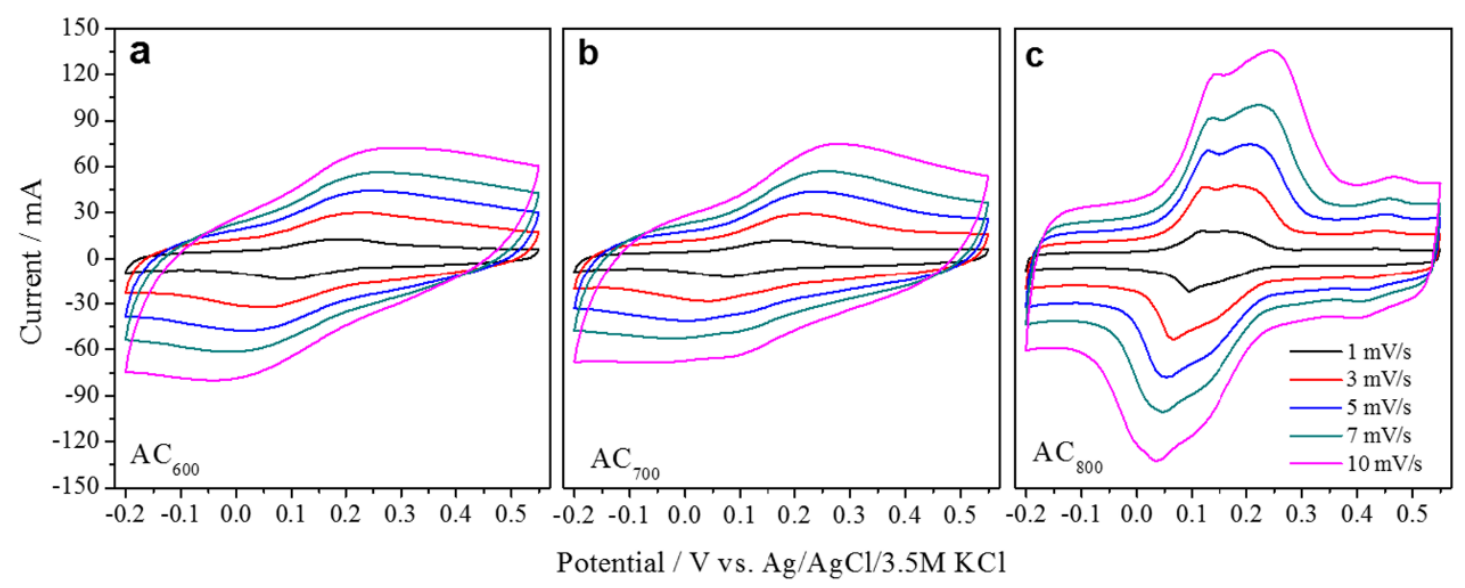

Figure 1. Cyclic voltammograms obtained in a three-electrode configuration for (a) $\mathrm{AC}_{600}$, (b) $\mathrm{AC}_{700}$, and (c) $\mathrm{AC}_{800}$ based electrodes, all of which contain adsorbed $\mathrm{MB}$ with $1 \mathrm{M} \mathrm{H}_{2} \mathrm{SO}_{4}$ as electrolyte.

The voltammograms clearly show the presence of two storage mechanisms, with oxidation and reduction peaks superimposed over a quadrangular profile, typical of electrostatic charge accumulation from carbon electrodes. ${ }^{24}$ In the case of $\mathrm{AC}_{800}$, the 
intensity of the peaks is much higher than in the case of the other carbons, due to the greater amount of $\mathrm{MB}$ adsorbed and the lower resistivity of this material. In addition, the faradaic processes in this electrode are more reversible as evidenced by analysis of the intensity $(i)$ and the difference in potentials between the oxidation and reduction peaks $(\Delta E)$. Table 1 summarizes these parameters for scan rate of $1 \mathrm{mV} \mathrm{s}^{-1}$.

Table 1. Electrochemical parameters obtained by cyclic voltammetry at $25{ }^{\circ} \mathrm{C}$ and at $1 \mathrm{mV} \mathrm{s}^{-1}$ for the activated carbons evaluated containing MB adsorbed.

\begin{tabular}{ccccc}
\hline Carbon & $I_{\text {ano }} / M a$ & $I_{\text {cat }} / m A$ & $\left|I_{\text {ano }} / I_{\text {cat }}\right|$ & $\Delta E / \mathrm{mV}$ \\
\hline $\mathrm{AC}_{600}$ & 12.7 & -13.8 & 0.92 & 97.3 \\
$\mathrm{AC}_{700}$ & 11.2 & -11.9 & 0.94 & 90.7 \\
$\mathrm{AC}_{800}$ & 18.2 & -18.7 & 0.97 & 63.5 \\
\hline
\end{tabular}

The data presented in Table 1 reveal that the voltammograms obtained with $\mathrm{AC}_{800}$ are the closest to a perfectly reversible system. The ratio between the intensities of the anodic and cathodic peaks $\left(\left|I_{\text {ano }} / I_{\text {cat }}\right|\right)$ are the closest to the unit and the $\Delta E$ values are the closest to $59 \mathrm{mV}$. These results therefore confirm that $\mathrm{CA}_{800}$ is the most suitable electrode material for a redox-SC containing $\mathrm{MB}$, with a fast and reversible electron transfer capability.

Electrochemical behavior of the redox-SC based on MB. In this section the electrochemical behavior of the redox-SC constructed with the best carbon $\left(\mathrm{AC}_{800}\right)$ is studied. This cell displays an interesting characteristic in its mode of charge accumulation, since there is no dominant mechanism during the constant charge/discharge processes. To clarify this issue, Figure 2 shows the galvanostatic curves at $0.2 \mathrm{~A} \mathrm{~g}^{-1}$ for the cell investigated in this study (a) $\left(\mathrm{CA}_{800} / \mathrm{MB}\left|\mathrm{H}_{2} \mathrm{SO}_{4}\right| \mathrm{CA}_{800} / \mathrm{MB}\right)$, (b) for the pure EDLC $\left(\mathrm{CA}_{800}\left|\mathrm{H}_{2} \mathrm{SO}_{4}\right| \mathrm{CA}_{800}\right),{ }^{23}$ and (c) for a well-known redox-SC used as a model, containing carbon nanotubes (CNT) as electrodes and hydroquinone (HQ) dissolved in the electrolyte $\left(\mathrm{CNT}\left|\mathrm{HQ} / \mathrm{H}_{2} \mathrm{SO}_{4}\right| \mathrm{CNT}\right){ }^{25}$ 


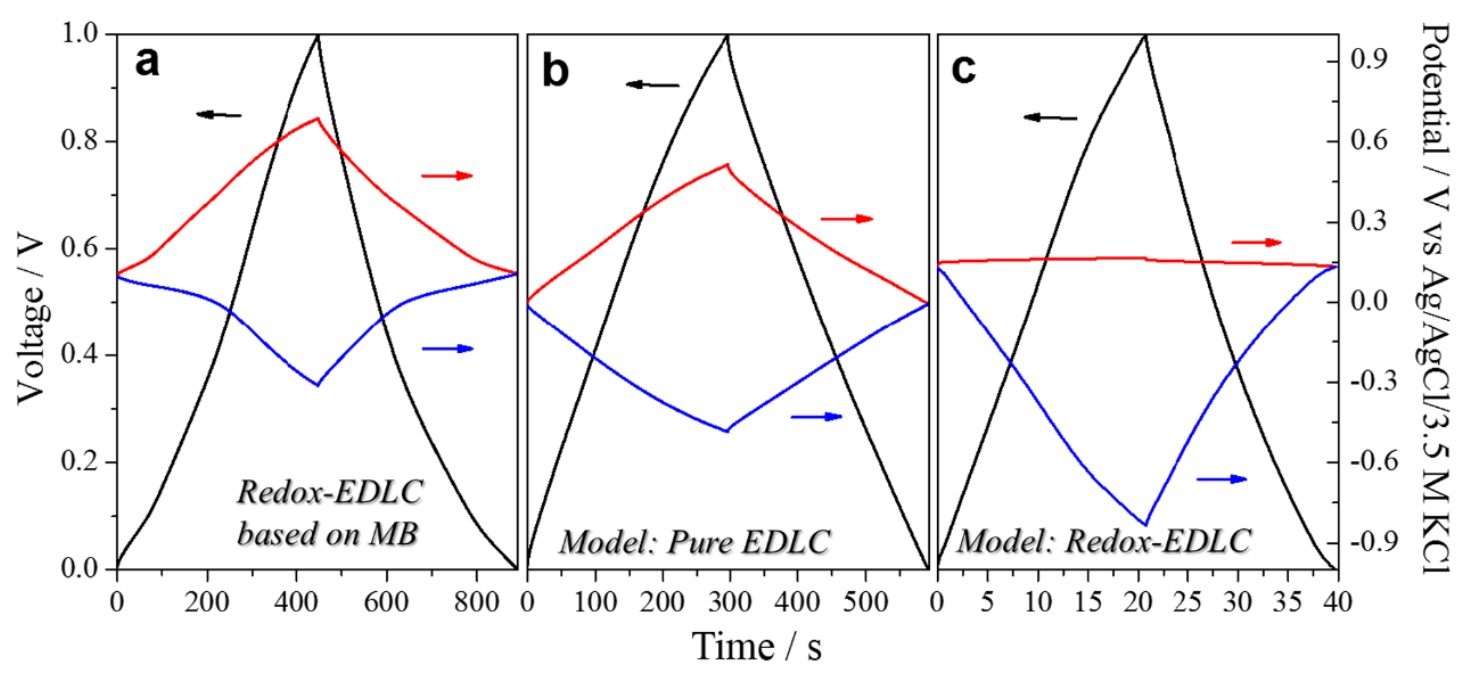

Figure 2. Galvanostatic charge/discharge profiles at $0.20 \mathrm{~A} \mathrm{~g}^{-1}$ for (a) the redox-SC based on MB, (b) pure EDLC and (c) a second redox-SC as model based on hydroquinone as redox shuttle and CNT as electrodes.

An examination of the potential profiles in Figure $2 b$ shows that the curves for pure EDCL are classical and characteristics of a symmetrical SC, with one single storage mechanism (an electric double layer) and with both electrodes having the same charge storage capacity. ${ }^{23}$ The model system presented in Figure $2 \mathrm{c}$ exhibits the behavior of a typical hybrid system, where the positive electrode is working at a constant potential based on the hydroquinone's formal potential (faradaic mechanism), while the negative electrode presents the triangular behavior typical of purely capacitive storage. ${ }^{25}$ However, the redox-SC based on MB (Figure 2a) is very different from the conventional mechanisms as it shows an asymmetric hybrid behavior. In this system none of the storage mechanisms is predominant in any of the electrodes. For this reason, no constant plateau is present in any of the potential curves and the two storage mechanisms (double layer formation and redox processes) operate simultaneously with similar kinetics, but with changes in magnitude over cycling, as will be shown in the next section. Here, it is important to note that this effect is peculiar to $\mathrm{MB}$, since the same asymmetric hybrid profile was also observed in cells containing CNTs as electrode in another published work with MB dissolved in the same electrolyte. ${ }^{26}$ It is still not fully understood how the electric double layer competes with the redox reaction in spite of the huge amount of adsorbed MB, but taking into account the large size of MB $(1.43 \mathrm{~nm} \times 0.61 \mathrm{~nm} \times 0.4 \mathrm{~nm}),{ }^{27-28}$ it is likely that the double layer forms in the smaller pores to which the MB has no access while the redox reaction only occurs in the larger pores, where $\mathrm{MB}$ is present. 
In fact, the interactions of $\mathrm{MB}$ on the surface of different carbons are intense, complex and have been the subject of many studies due to the numerous applications in which $\mathrm{MB}$ can be employed. ${ }^{28-30}$ A macroscopic example that reflects the intensity of the interactions was showed with the high adsorption capacity in the $\mathrm{AC}_{800}$, reaching $1042 \mathrm{mg} \mathrm{g}^{-1}{ }^{23}$ Yan et al. showed that the interaction between MB and carbon nanotubes is so stable that the composite is preserved even after filtering, drying and its ultrasound redispersion in water. ${ }^{31}$ Another interesting example of the complexity of these interactions can be seen in the work of Barreda et al., which has experimentally shown that activated carbons are able to reorient their graphite micro-domains after the adsorption of this cationic dye. ${ }^{32}$ As will be seen in the present paper, these microscopic effects also influence the performance of the redox-SC.

Further details of the mechanism of charge accumulation of this redox-SC can be obtained from EIS measurements. Figure 3 shows the Nyquist diagrams corresponding to (a) the cell, (b) the positive electrode and (c) the negative electrode of the pure EDLC and redox-SC.

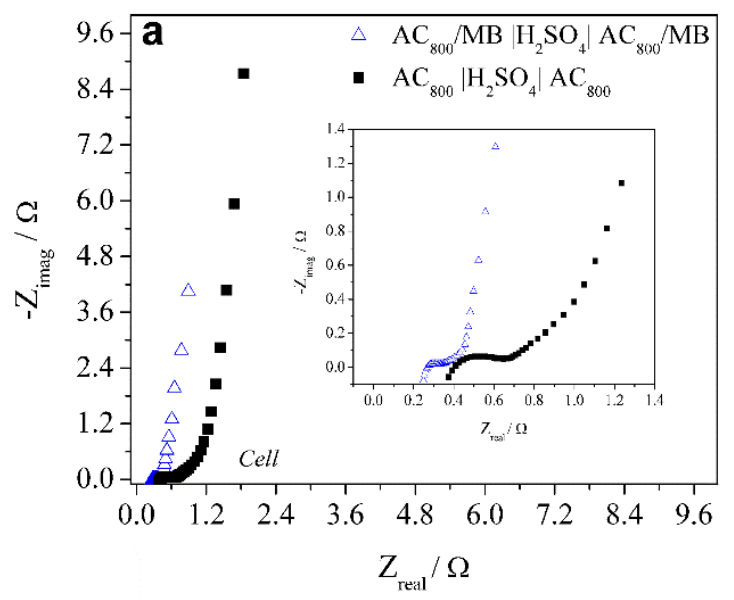



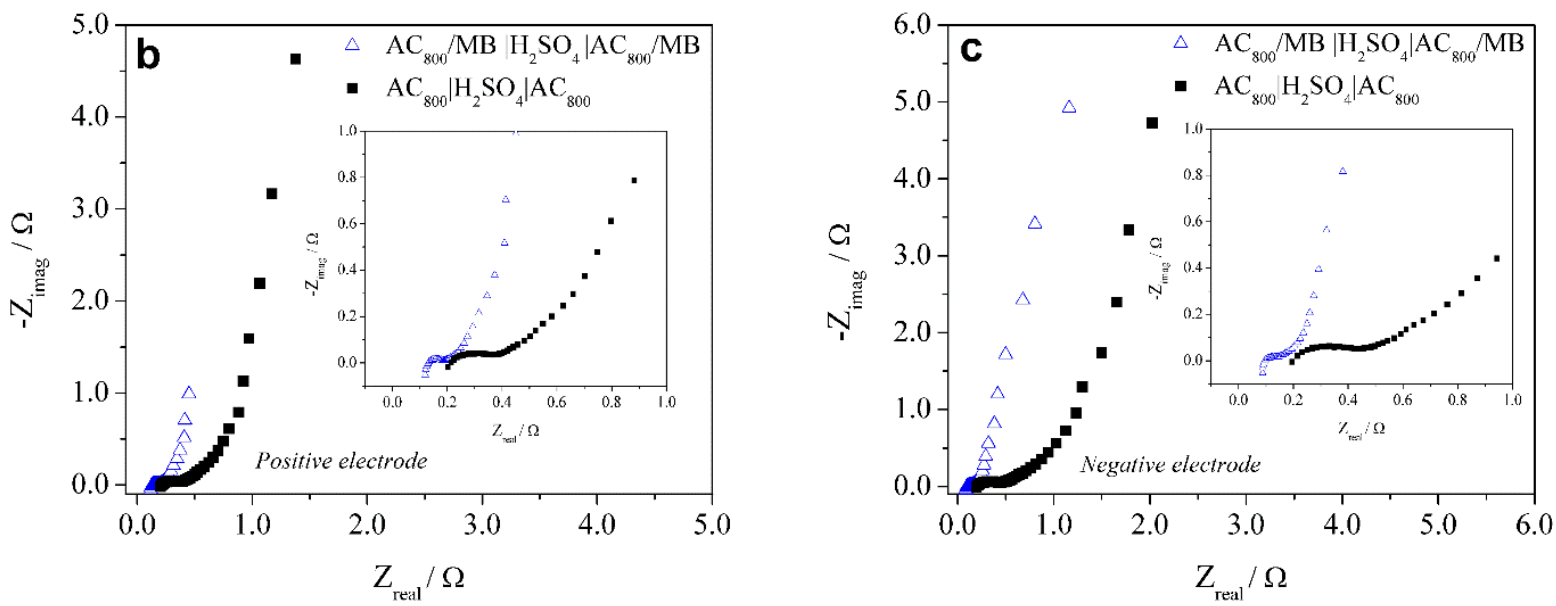

Figure 3. Nyquist diagrams obtained from EIS for the pure EDLC (black dots) and redox-SC (blue dots). Diagram corresponding to (a) the cell, (b) the positive electrode and (c) the negative electrode.

The information obtained from this diagram for capacitor cells (Figure 3a) can be summed up as follows. The first point of the plot, where $-Z_{\text {imag }}=0$, is normally attributed to the resistance of the electrolyte but, in our opinion, the interaction of the electrolyte with the electrode surface must also be contributing to the resistance. The diameter of the semicircle is often associated with electrode resistance, which is the resistance of the electrode plus contact resistance from the current collector. The knee, that normally appears at $45^{\circ}$, is associated to resistance to the diffusion of the electrolyte in the porous network. Finally, at the lower frequencies, a straight line, that should ideally be perpendicular, appears as a consequence of the formation of the electric double layer on the surface. The real slope is also associated to the electrolyte ions experiencing diffusion problems. Paradoxically, all the processes associated with the redox-SC show a lower resistance than the processes associated with the pure electric double layer formation, for both electrodes. This is somewhat unusual as redox processes are normally considered more resistive than capacitive processes. It is also paradoxical that the resistances to diffusion are greater with empty pores than with pores full of MB.

More information can be obtained from the separate impedance spectra of the positive and negative electrodes. Figures $3 \mathrm{~b}$ and c confirm that the electrodes containing $\mathrm{MB}$ are less resistive than the free carbon, both in terms of the conductivity of the material (semicircle) and the diffusion processes $\left(45^{\circ}\right.$ line). It is also clear from the diagrams that the processes occurring in the negative electrode (with and without MB) 
are more resistive that the processes occurring in the positive one. It is tempting to assign the greater resistance of the negative electrode to the MB redox reactions, but in this case the resistance is even higher in the free carbon, where no MB is present. The high resistance therefore must be due to the diffusion of positive charges when forming the electric double layer. It is likely that in an acidic medium the carbon surface is positively charged (oxygen functional groups might be protonated) and so the formation of the electric double layer with cations is more hindered than the formation of the double layer with anions.

To summarize, the free carbon accumulates charge via the formation of an electric double layer, while the $\mathrm{AC} / \mathrm{MB}$ accumulates charge via two mechanisms, electric double layer formation and MB reversible redox reactions. Nevertheless, the processes that occur in the $\mathrm{AC} / \mathrm{MB}$ (a carbon with a porosity full of $\mathrm{MB}$ ) are less resistive both in the positive and negative electrodes, attending both the conductivity of the material and the diffusion processes involved. It is difficult to understand how the presence of $\mathrm{MB}$ in the pore structure of the carbon improves the conductivity of the material and facilitates the diffusion of ions through the porous network. It is possible that the presence of $\mathrm{MB}$ inside the porosity allows charge to accumulate with only a very limited movement of the ions or molecules. Redox processes involving MB only need the diffusion of protons to occur as the MB is already adsorbed onto the electrode surface. In the formation of the double layer it is also possible that the chloride ions, which accompany $\mathrm{MB}$ when it is adsorbed, form the double layer in the positive electrode, making the diffusion of $\mathrm{HSO}_{4}{ }^{-}$from the electrolyte unnecessary.

A second explanation for this anomalous experimental behavior can be found in a paper only recently published, which demonstrates that the adsorption of $\mathrm{MB}$ changes the crystalline structure of the carbon, and in turn its electrical conductivity and porous network. ${ }^{32}$ To explain why the electrodes containing MB are less resistive, Figure 4 shows the $\mathrm{XRD}$ pattern for $\mathrm{AC}_{800}$ before and after $\mathrm{MB}$ adsorption. 


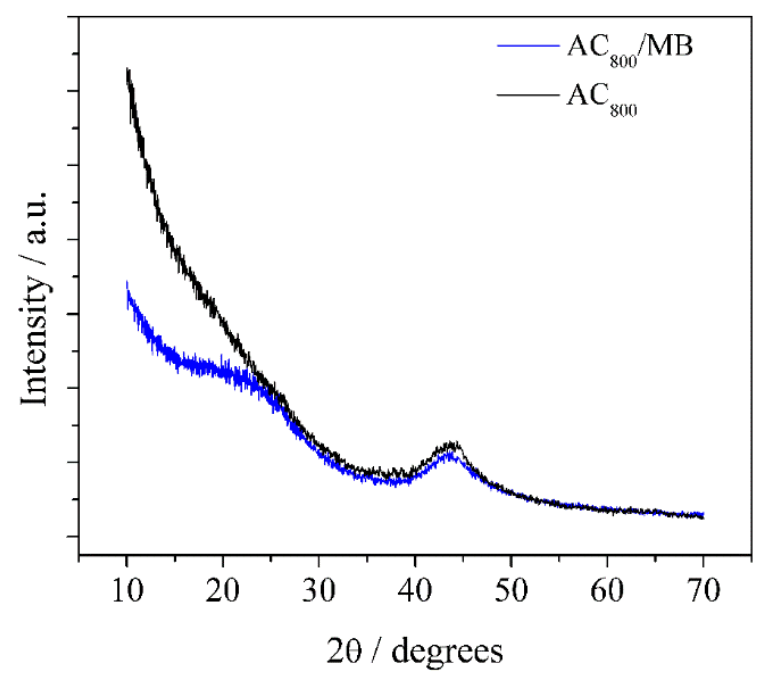

Figure 4. $\mathrm{XRD}$ pattern for the $\mathrm{AC}_{800}$ sample before and after the adsorption of methylene blue.

The broad reflection of the (002) plane which is centered at around $23^{\circ}$ is characteristic of graphite microdomains and practically does not appear in $\mathrm{AC}_{800}$ due to its low crystallinity. However, with the adsorption of MB there is a noticeable increase in the intensity of the (002) diffraction peak indicating the reorientation to some extent of the graphitic carbon domains upon adsorption. As previously mentioned, this rare effect was recently reported by Barreda et al., when adsorbing MB and n-nonane onto petroleum-pitch derived activated carbon. ${ }^{32}$ The same authors also observed an increase in interlayer spacing with the adsorption of MB. The same effects which have a direct bearing on the properties of the redox-SC were also observed in the activated carbons used in the present study. The enhanced resistance can be also explained by the rearrangement of the crystalline structure of the carbon when the MB is adsorbed. In addition, the expansion of the porous structure might be expected to facilitate the diffusion of electrolyte ions and the formation of the electric double layer, despite the pores being full of MB, corroborating the profile observed in the galvanostatic curves.

Performance quantification and cyclability. The performance of this MB-based redox-SC changes considerably with cycling. By means of synchronous cyclic chronopotenciometry, which records the cell voltage and the potential of each electrode simultaneously, it is possible to monitor any variations and draw inferences about the processes that occur in each electrode. Considering the initial performance of the device, the electrochemical parameters are presented in Table 2 at $0.20 \mathrm{~A} \mathrm{~g}^{-1}$ for the $50^{\text {th }}$ 
cycle. To facilitate comparison, data for the pure EDLC are also shown under the same conditions.

Table 2. Electrochemical data calculated for the $50^{\text {th }}$ cycle from the galvanostatic experiments carried out at $0.20 \mathrm{~A} \mathrm{~g}^{-1}$ for EDLC and redox-SC.

\begin{tabular}{cccccccc} 
Cell & $C_{\text {cell }} / \mathrm{F} \mathrm{g}^{-1}$ & $C_{+} / \mathrm{F} \mathrm{g}^{-1}$ & $C_{-} / \mathrm{F} \mathrm{g}^{-1}$ & $E / \mathrm{W} \mathrm{h} \mathrm{kg}^{-1}$ & $P / \mathrm{W} \mathrm{kg}^{-1}$ & $E S R / \Omega$ & $\varepsilon / \%$ \\
\hline EDLC & 54.3 & 208.5 & 225.0 & 7.4 & 90.0 & 1.2 & 99.4 \\
Redox-SC & 77.9 & 242.6 & 438.6 & 10.7 & 87.3 & 0.7 & 99.0 \\
\hline
\end{tabular}

In the initial cycles, the use of $\mathrm{MB}$ as redox shuttle causes a significant increase in the capacitance and energy density by 43 and 44\%, respectively, compared to the pure EDLC. This result is mainly due to the increase in the capacitance of the negative electrode from 225.0 to $438.6 \mathrm{~F} \mathrm{~g}^{-1}$. Similar values for the capacitance of the electrode and energy density of the cell (of the order of $400 \mathrm{~F} \mathrm{~g}^{-1}$ and $10 \mathrm{~W} \mathrm{~h} \mathrm{~kg}^{-1}$, respectively) are also found in works that employ other organic molecules as redox shuttle such as: methyl viologen, p-phenylenediamine, anthraquinonedisulphonate, 1,10-phenanthroline, and hydroquinone. ${ }^{10,13,33-35}$

An analysis of Figure 2a, corresponding to the galvanostatic curves for the 50th cycle, shows that the negative electrode presents the greatest distortion in linearity. As stated in the previous section, this distortion is due to the redox reactions of MB that occur in this electrode. The strong adsorption of MB has no bearing on the values of $P$, which practically do not change when both cells are compared. This result confirms that the kinetics of the electric double layer and the redox reactions are similar in this redoxSC. It should also be noted that the ESR values agree with the results obtained from the EIS measurements. With the decrease of all resistive events in both electrodes after the adsorption of $\mathrm{MB}$, the total resistance of the redox-SC $(0.7 \Omega)$ is less than the value calculated for the pure EDLC (1.2 $\Omega$ ). Considering other redox-SCs, the cell that combines the $\mathrm{AC}_{800}$ and the $\mathrm{MB}$ presents lower ESR values than systems prepared with different electrode/electrolyte combinations containing p-phenylenediamine (6.82 $\Omega$ ) and anthraquinonedisulphonate $(15.3 \Omega)$, for example. ${ }^{34-35}$

Also worth noting is the rate capability of these cells in order to be able to evaluate the behavior of the redox SC in more demanding conditions (in terms of power) and whether the adsorption of MB really does have a positive influence on the kinetics of the cell. Figure 5 shows the behavior of both SCs in terms of (a) energy and (b) power densities at different current densities. 

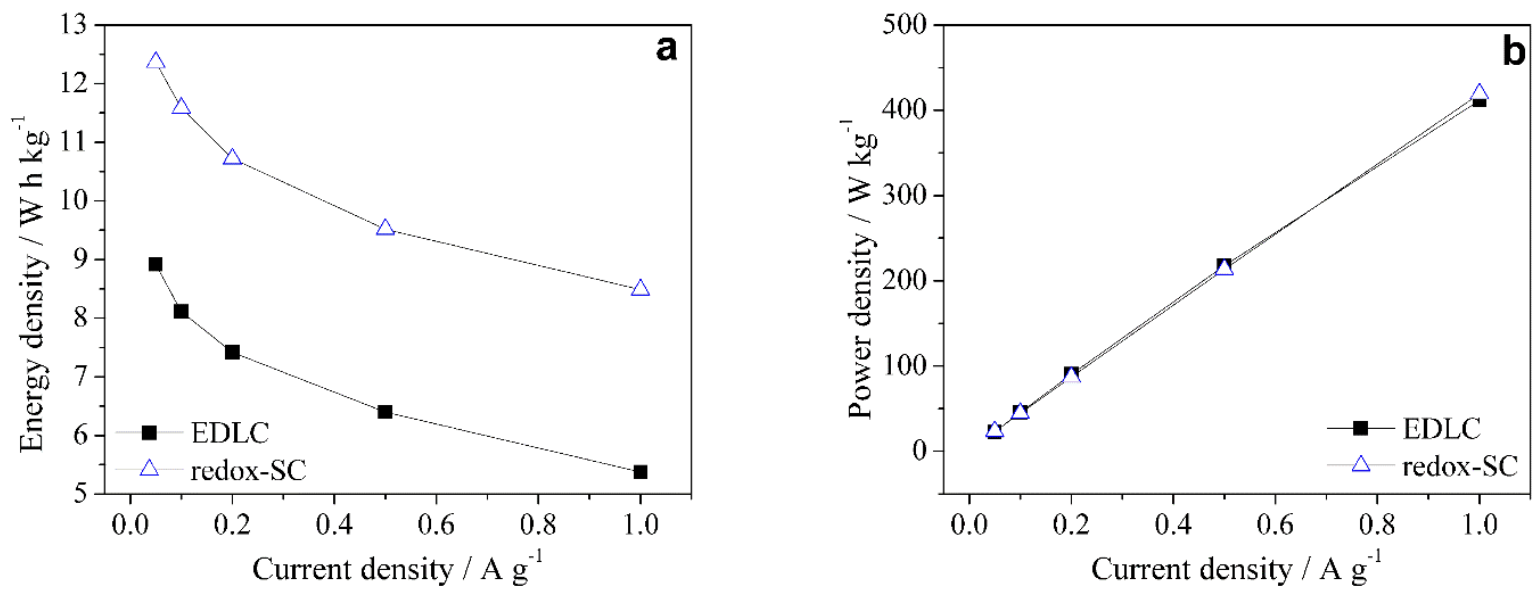

Figure 5. (a) Energy density and (b) power density of the SCs at different current densities.

Both in the redox-SC and in the pure EDLC, the $E$ values decrease gradually with increasing current density. This is an unavoidable consequence of intrinsic cell resistance. The redox-SC always has a higher energy density and retains about $68 \%$ of its energy density while the pure EDLC retains about $60 \%$ at $1.0 \mathrm{~A} \mathrm{~g}^{-1}$, in relation to $0.05 \mathrm{~A} \mathrm{~g}^{-1}$. This result, at first, might appear contradictory because normally faradaic processes are kinetically slower compared to the formation of the electric double layer. But, again, this result corroborates the data obtained from the EIS, DRX and ESR measurements. The strong adsorption of the MB, that decreases the resistance of the diffusion processes in the electrodes, leads to a smaller loss of energy at higher current densities. This highlights the energy superiority of the redox-SC as it is able to provide a very high energy density $\left(8.5 \mathrm{~W} \mathrm{~h} \mathrm{~kg}^{-1}\right)$ at a high power density $\left(419.3 \mathrm{~W} \mathrm{~kg}^{-1}\right)$, whereas the conventional cell is only able to display a similar performance in energy density (8.9 $\mathrm{W} \mathrm{h} \mathrm{kg}{ }^{-1}$ ) at $45.7 \mathrm{~W} \mathrm{~kg}^{-1}$.

An analysis of this redox-SC in later cycles reveals an additional element of complexity. Figure 6 shows the behavior of the energy density of the device over cycling at $0.2 \mathrm{~A} \mathrm{~g}^{-1}$. It should be noted that this cell is not stable and shows anomalous behavior as the energy density increases constantly until approximately the 1460th cycle. After that cycle the cell fails. 


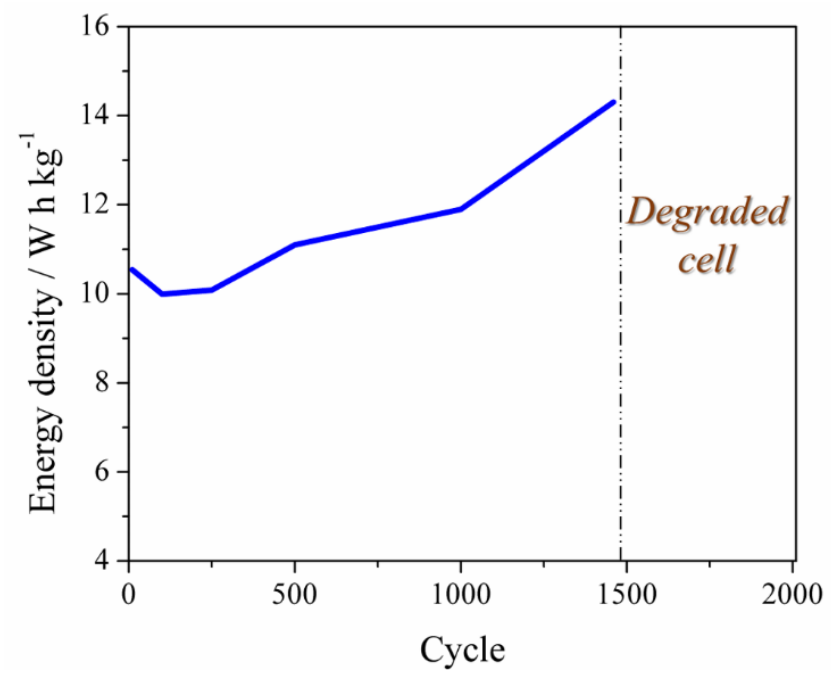

Figure 6. Cycling performance at $0.2 \mathrm{~A} \mathrm{~g}^{-1}$ for a redox-SC based on methylene blue.

Cycling stability is a drawback for the redox-SC developed in this work. Other redox-SCs reported in the literature, containing organic and inorganic additives, are capable of exceeding 5000 cycles with retention above $70 \% .^{13,18,33,36}$ To understand the cycling behavior of this cell based on MB it is important to follow the evolution of the potential curves. Figure 7 shows the galvanostatic curves for the redox-SC at cycle numbers 100, 500, 1000, 1460.

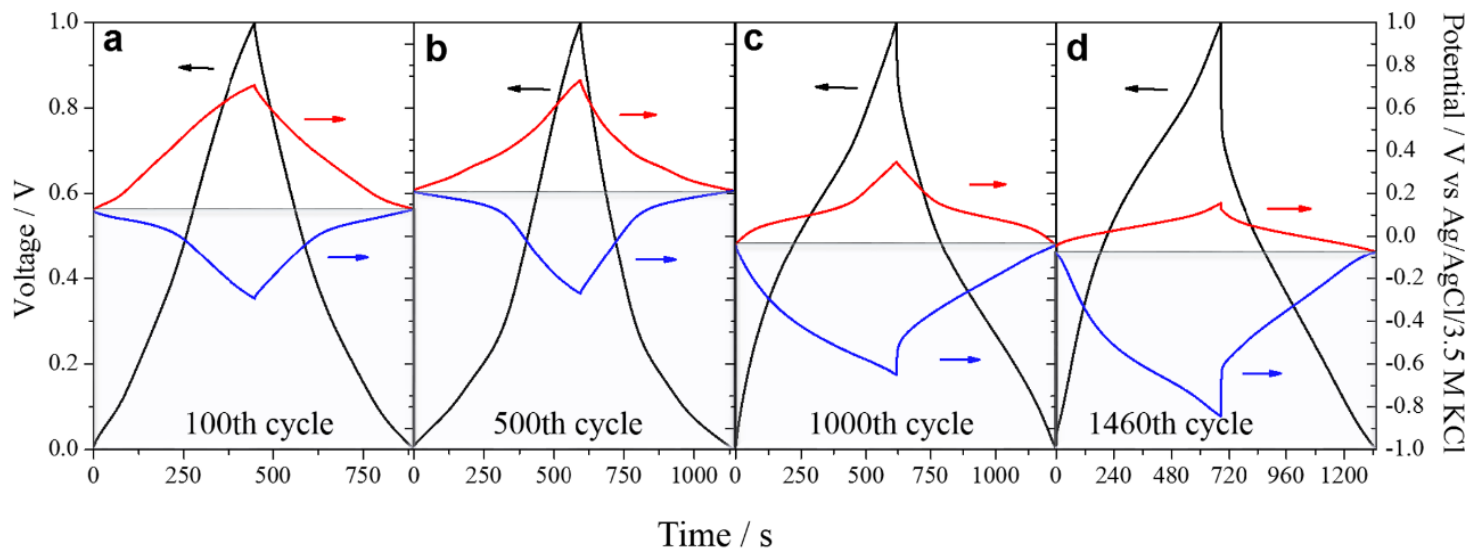

Figure 7. Galvanostatic charge/discharge profiles obtained at $0.20 \mathrm{~A} \mathrm{~g}^{-1}$ for the redox SC. (a) Cycle 100, (b) 500, (c) 1000, (d) and 1460.

In the analysis of the profiles of the potential curves for this redox-SC, two series of events must be highlighted to explain the electrochemical instability of this cell: (i) changes to the extent of the redox reactions in both electrodes; (ii) changes to the equilibrium potential. 
The changes in slope in the potential curves reflect the changes in the extent of the redox reactions, which initially occur in the negative electrode and gradually begin to appear in the positive one. An examination of the electrochemical parameters helps to understand these changes. The capacitance values of the electrodes reveal different behaviors in the positive and negative electrode over cycling (Table 3 ).

Table 3. Electrochemical data for the redox-SC calculated for the different cycles from the galvanostatic experiments carried out at $0.20 \mathrm{~A} \mathrm{~g}^{-1}$.

\begin{tabular}{cccccccc}
\hline Cycle & $C_{\text {cell }} / \mathrm{F} \mathrm{g}^{-1}$ & $C_{+} / \mathrm{F} \mathrm{g}^{-1}$ & $C_{\text {. }} / \mathrm{F} \mathrm{g}^{-1}$ & $E / \mathrm{W} \mathrm{h} \mathrm{kg}^{-1}$ & $P / \mathrm{W} \mathrm{kg}^{-1}$ & $E S R / \Omega$ & $\varepsilon / \%$ \\
\hline 100 & 73.0 & 247.9 & 358.5 & 10.1 & 81.5 & 0.7 & 99.0 \\
500 & 80.6 & 369.7 & 285.7 & 11.1 & 78.2 & 1.1 & 96.0 \\
1000 & 85.9 & 485.6 & 274.5 & 11.7 & 72.8 & 2.5 & 95.6 \\
1460 & 114.1 & 1897.5 & 253.9 & 14.3 & 69.6 & 7.2 & 91.3 \\
\hline
\end{tabular}

The positive electrode, which was initially the most capacitive as reflected in its linear galvanostatic curves, gradually modifies it behavior until it begins to operate with a battery-like mechanism, as is evidenced by the more constant potential curves during the final cycles. Of special interest are the variations in the $C_{+}$values which in the last cycle reach their maximum $\left(1897.5 \mathrm{~F} \mathrm{~g}^{-1}\right)$, and explain the increase in $C_{\text {cell }}$ and $E$. The greater extension of the faradaic reactions and the increase in ESR also explain the decrease in the $P$ values. In contrast, the negative electrode gradually becomes more capacitive until its capacitance values are reduced to the level of the pure EDLC.

The equilibrium potentials (recorded at a voltage of $0 \mathrm{~V}$ ) give indirect clues as to why these changes in mechanism occur in the electrodes. In the pure EDLC, the potentials are close to zero and are the result of the charge asymmetries between electrode/electrolyte interfaces. In batteries and redox-SC, these equilibrium potentials normally correspond to the formal potentials governed by Nernst's law. In the redox-SC of this study the equilibrium potential during first few hundreds of cycles corresponds to the formal potential of the $\mathrm{MB}$ in the acidic media and on the $\mathrm{AC}_{800}$ interface $(0.16 \mathrm{~V}$ vs. $\mathrm{Ag} / \mathrm{AgCl} / \mathrm{KCl} 3.5 \mathrm{M})$. As the cycling progresses these potentials are modified slightly indicating substantial changes at the electrode/electrolyte interface. This is due to the degradation of the electrode and/or electrolyte and $\mathrm{MB}$ secondary reactions that can modify the equilibrium potentials. Judging from the changes in the profiles of the potential curves of this redox-SC, a series of chemical reactions with MB must be the main cause, as will be shown in the next section. 
One negative consequence of the changes in the equilibrium potentials is the modification of the operational potential ranges of the electrodes. In the case of this cell it should be noted that in the final cycles the negative electrode operates outside the electrochemical stability window of water, and reaches very low potentials (below -0.8 $\mathrm{V}$ vs. $\mathrm{Ag} / \mathrm{AgCl} / \mathrm{KCl} 3.5 \mathrm{M}$ ). This causes an excessive degradation of the electrode and in turn of the cell, and explains the increase in the ESR values and the decrease in coulombic efficiency $(\varepsilon)$. At these potentials hydrogen evolves out of the decomposition of water until the cell becomes totally inoperative after a small number of cycles.

Degradation of the MB in the redox-SC. This section considers the molecular origin of the degradation of redox-SC electrodes with cycling. These processes generate instability in the performance of the cell and cause fading. The galvanostatic curves in Figure 7 show that the faradaic reactions not only derive from the previously adsorbed MB molecules but also from the equilibrium potentials of the system that change over the cycles indicating that new species are produced in the cell with different formal potentials capable of exchanging electrons at the $\mathrm{AC}_{800}$ interface. To investigate the formation of these new species, the electrodes were collected (before and after cycling experiments) and analyzed by ESI-MS. Figure 8 shows the ESI-MS spectra for (a) $\mathrm{AC}_{800}$, (b) for the $\mathrm{AC}_{800}$ containing adsorbed $\mathrm{MB}$ before cycling, and for (c) positive and (d) negative electrodes after complete electrochemical degradation of the cell. To facilitate comparison, only the $\mathrm{m} / \mathrm{z}$ range between 200 and 400 is shown. The complete spectra can be found in Figure S2 (see SI).
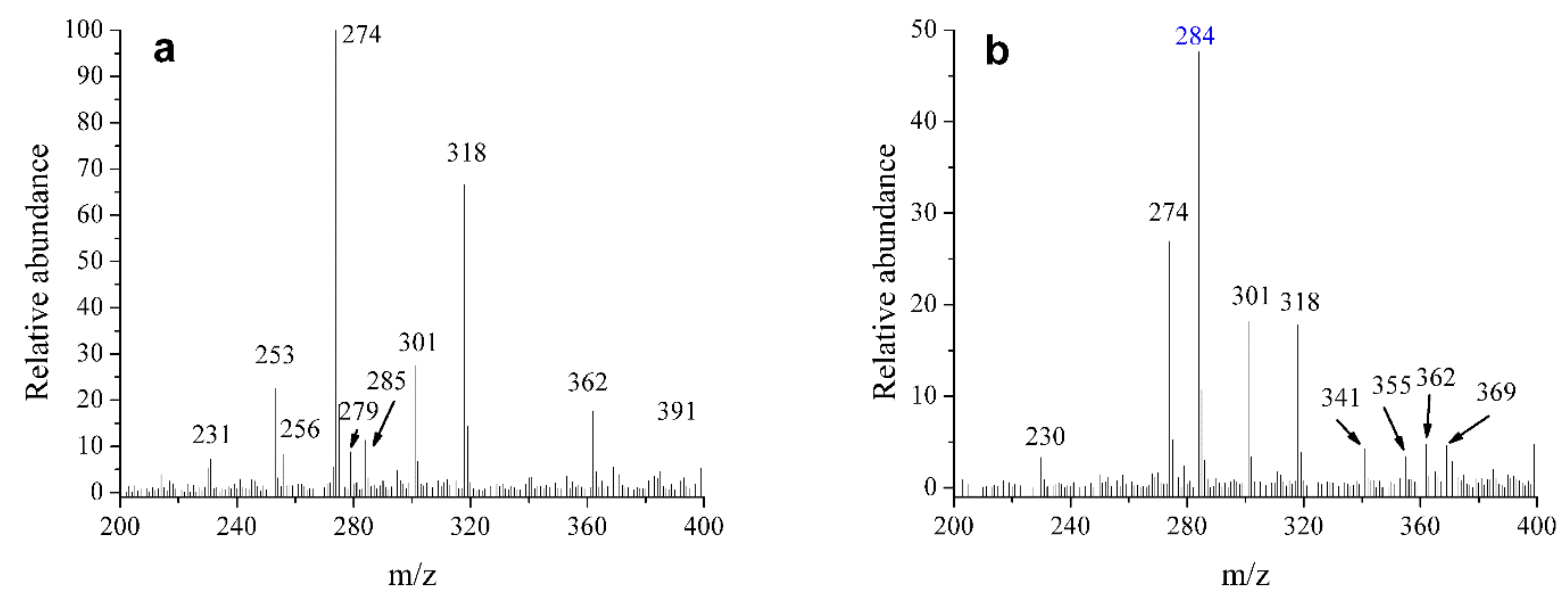

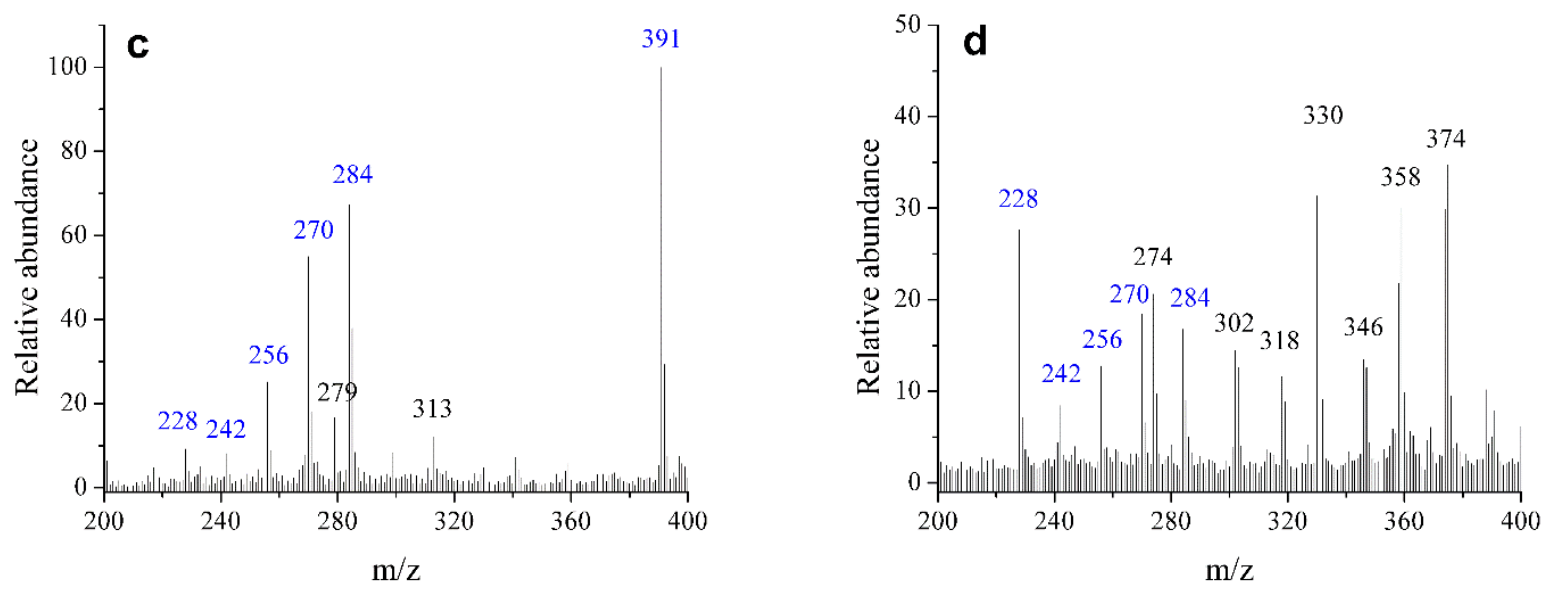

Figure 8. (a) ESI-MS spectra from the extraction of the pure carbon, (b) carbon containing MB adsorbed before cycling, and for (c) positive and (d) negative electrodes after cycling. The values of $\mathrm{m} / \mathrm{z}$ in blue correspond to MB and its degradation products.

In the case of the pure carbon (Figure 8a) there are quite a number of signals corresponding to fragmented carbonaceous materials and many of these signals are also present in the spectra of the electrodes containing MB. With the adsorption of $\mathrm{MB}$, an intense signal appears at $\mathrm{m} / \mathrm{z}=284$, corresponding to a MB cation (Figure $8 \mathrm{~b}$ ). After cycling new signals appear in the region between $\mathrm{m} / \mathrm{z} 200-400$ in both electrodes. There are four important new signals that are not observed in Figure 8a and $\mathrm{b}$. The pattern of these peaks suggests the occurrence of a $\mathrm{N}$-demethylation process and the signals can be observed at $\mathrm{m} / \mathrm{z}=270,256,242$ and 228 corresponding to Azure B (AB), Azure A (AA), Azure C (AC) and Thionime (Th), respectively. These MB fragmentation patterns have been studied by several authors under different degradation conditions. ${ }^{20-21,}$ 37-38 The acid medium is rich in protons, electrophilic species, which can attack methyl groups and electron-donor substituents. A schematic representation of the $\mathrm{N}$ demethylation process is shown in Figure 9a. In addition to the demethylation peaks, other peaks related to the oxidation products of MB can be observed: an intense peak at $\mathrm{m} / \mathrm{z}=391$ together with a smaller one $(\mathrm{m} / \mathrm{z}=392)$ that may correspond to MB oxidized species (Figure 9b). 

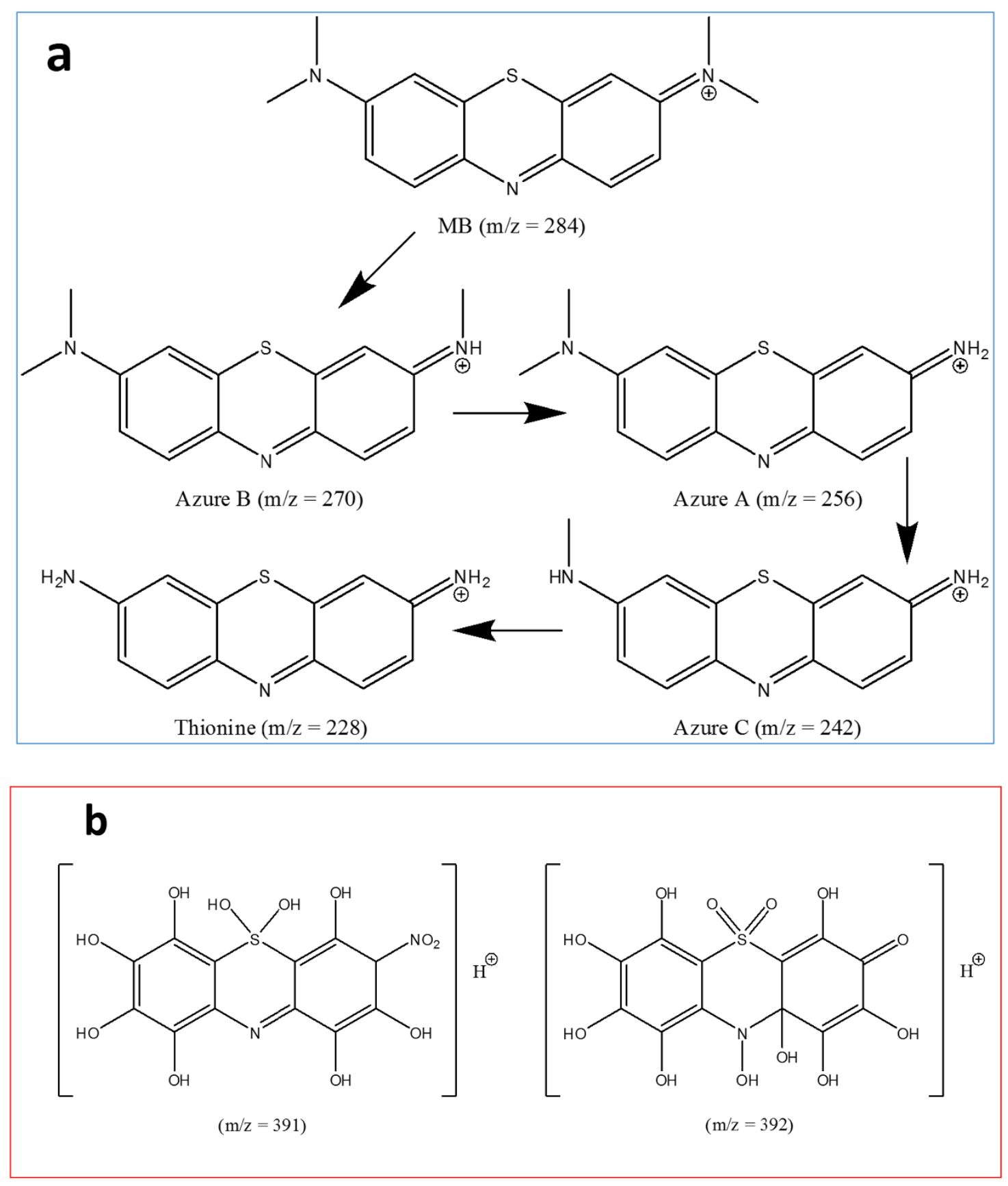

Figure 9. (a) Species obtained by successive N-demethylation of $\mathrm{MB}$ on the $\mathrm{AC}$ electrodes and acidic medium. (b) Proposed structures for MB oxidized species.

Also worth studying is the fragmentation profile of the $\mathrm{MB}$ in the negative electrode. It should be noted that the progressive degradation of the MB in this electrode is more intense than in the positive one and that Thionine $(\mathrm{m} / \mathrm{z}=228)$, the most reduced compound of the series, shows the most intense signal. The two electrodes have different populations of these demethylation products, which maintain the aromatic structure of $\mathrm{MB}$, are rich in electrons and can undergo redox processes. This explains 
why the cell is unstable, since different species form during the cycling in the different electrodes, modifying the extent of the redox reactions and the equilibrium potentials. However, it is difficult to know exactly which species are dominating the faradaic mechanism at each moment of the cycling, and these results only serve to show that MB is not a shuttle redox that is suitable for constructing a cell for practical applications. For the practical application of a shuttle redox its thermodynamic stability in the operating conditions is a must. This work has shown that despite its initial improvement in performance, $\mathrm{MB}$ is not stable at the high potentials reached by the electrodes in an acid medium, since its structure is seriously modified which leads to the premature degradation of the device.

\section{Conclusions}

In this work a complete study of a redox-SC based on MB has been performed. $\mathrm{MB}$ is strongly adsorbed in large amounts by $\mathrm{AC}_{800}$. However, the faradaic mechanism is not predominant in either electrode and the storage mechanism of this cell is mixed. As a result, $\mathrm{MB}$ improves the energy density of the cell by managing to maintain the power density of the conventional EDLC. In addition, XRD and EIS measurements have revealed other surprising effects of this redox additive. MB affects the structure of the $\mathrm{AC}_{800}$ by reorganizing its micro-domains, decreasing electrode and cell resistance, and contributing to the kinetics of the faradaic process.

On the other hand, measurements of the electrode potentials over cycling have revealed abrupt changes in the mechanism of charge accumulation in each electrode, which correlates with the instability of the redox shuttle. This finding is original and has been confirmed by ESI-MS measurements that revealed the demethylation of MB during cell cycling. The gradual decomposition of $\mathrm{MB}$ formed byproducts in different proportions in each electrode. This destabilized the cell, altering its potentials of operation and the extent of the redox reactions, and led to the rapid degradation of the cell before the completion of 1500 cycles.

\section{Acknowledgments}

The authors would like to thank the Conselho Nacional de Desenvolvimento Científico e Tecnológico (CNPq) - Brazil for the financial support (PVE 2014, process number 400714/2014-0). Financial support from Ministerio de Economía, Industria y 
Competitividad (project MAT2016-77114-R) and Principado de Asturias (Fondo Europeo de Desarrollo Regional (GRUPIN 14-118). The authors are also thankful to the Instituto Nacional de Ciência e Tecnologia em Nanomateriais de Carbono - INCT Nanocarbono. Fabiano G. F. de Paula and Mateus C. M. de Castro thankfully acknowledge the scholarships received from CNPq.

\section{References}

(1) International Energy Agency, Technology Roadmap: Electric and Plug-in Hybrid Electric Vehicles; International Energy Agency: Paris, 2011.

(2) Grbovié, P. J. Ultra-Capacitors in Power Conversion Systems: Applications, Analysis, and Design from Theory to Practice, 1st ed; Wiley: UK, 2014.

(3) Conway, B. E. Electrochemical Supercapacitors: Scientific Fundamentals and Technological Applications, 1st ed; Springer: New York, 1999.

(4) Dubal, D. P.; Ayyad, O.; Ruiz, V.; Gomez-Romero, P. Hybrid Energy Storage: The Merging of Battery and Supercapacitor Chemistries. Chem. Soc. Rev. 2015, 44, 1777-1790.

(5) Naoi, K.; Ishimoto, S.; Miyamoto, J.; Naoi, W. Second Generation 'Nanohybrid Supercapacitor': Evolution of Capacitive Energy Storage Devices. Energy Environ. Sci. 2012, 5, 9363-9373.

(6) Cui, C.; Qian, W.; Yu, Y.; Kong, C.; Yu, B.; Xiang, L.; Wei, F. Highly Electroconductive Mesoporous Graphene Nanofibers and Their Capacitance Performance at 4 V. J. Am. Chem. Soc. 2014, 136, 2256-2259.

(7) Liu, R.; Lee, S. B. MnO2/Poly(3,4-ethylenedioxythiophene) Coaxial Nanowires by One-Step Coelectrodeposition for Electrochemical Energy Storage. J. Am. Chem. Soc. 2008, 130, 2942-2943.

(8) Ortega, P. F. R.; dos Santos Junior, G. A.; Montoro, L. A.; Silva, G. G.; Blanco, C.; Santamaría, R.; Lavall, R. L. LiFePO4/Mesoporous Carbon Hybrid Supercapacitor Based on LiTFSI/Imidazolium Ionic Liquid Electrolyte. J. Phys. Chem. C 2018, 122, 1456-1465.

(9) Wang, Y. G.; Zhou, D. D.; Zhao, D.; Hou, M. Y.; Wang, C. X.; Xia, Y. Y. High Performance Hybrid Supercapacitor Based on Graphene-Supported $\mathrm{Ni}(\mathrm{OH})(2)$ Nanowires and Ordered Mesoporous Carbon CMK-5. J. Electrochem. Soc. 2013, 160, A98-A104.

(10) Roldan, S.; Blanco, C.; Granda, M.; Menendez, R.; Santamaria, R. Towards a Further Generation of High-Energy Carbon-Based Capacitors by Using Redox-Active Electrolytes. Angew. Chem. Int. Ed. 2011, 50, 1699-1701. 
(11) Sathyamoorthi, S.; Kanagaraj, M.; Kathiresan, M.; Suryanarayanan, V.; Velayutham, D. Ethyl Viologen Dibromide as a Novel Dual Redox Shuttle for Supercapacitors. J. Mater. Chem. A 2016, 4, 4562-4569.

(12) Navalpotro, P.; Palma, J.; Anderson, M.; Marcilla, R. High Performance Hybrid Supercapacitors by using Para-Benzoquinone Ionic Liquid Redox Electrolyte. J. Power Sources 2016, 306, 711-717.

(13) Chun, S. E.; Evanko, B.; Wang, X. F.; Vonlanthen, D.; Ji, X. L.; Stucky, G. D.; Boettcher, S. W. Design of Aqueous Redox-Enhanced Electrochemical Capacitors with High Specific Energies and Slow Self-Discharge. Nat. Commun. 2015, 6, 1-10.

(14) Ortega, P. F. R.; González, Z.; Blanco, C.; Silva, G. G.; Lavall, R. L.; Santamaría, R. Biliquid Supercapacitors: a Simple and New Strategy to Enhance Energy Density in Asymmetric/Hybrid Devices. Electrochim. Acta 2017, 254, 384-392.

(15) Diaz, P.; Gonzalez, Z.; Santamaria, R.; Granda, M.; Menendez, R.; Blanco, C. Enhanced Energy Density of Carbon-Based Supercapacitors using Cerium (III) Sulphate as Inorganic Redox Electrolyte. Electrochim. Acta 2015, 168, 277-284.

(16) Frackowiak, E.; Beguin, F. Carbon Materials for the Electrochemical Storage of Energy in Capacitors. Carbon 2001, 39, 937-950.

(17) Béguin, F.; Frackowiak, E. Supercapacitors: Materials, Systems, and Applications, 1st ed; Wiley: Singapore, 2013.

(18) Diaz, P.; Gonzalez, Z.; Santamaria, R.; Granda, M.; Menendez, R.; Blanco, C. Optimization of a Carbon-Based Hybrid Energy Storage Device with Cerium (III) Sulfate as Redox Electrolyte. J. Power Sources 2016, 309, 50-55.

(19) Montes-Navajas, P.; Asenjo, N. G.; Santamaría, R.; Menéndez, R.; Corma, A.; García, H. Surface Area Measurement of Graphene Oxide in Aqueous Solutions. Langmuir 2013, 29, 13443-13448.

(20) Sohrabnezhad, S. Study of Catalytic Reduction and Photodegradation of Methylene Blue by Heterogeneous Catalyst. Spectrochim. Acta A 2011, 81, 228-235.

(21) Kuan, W.-H.; Chan, Y.-C. pH-Dependent Mechanisms of Methylene Blue Reacting with Tunneled Manganese Oxide Pyrolusite. J. Hazard. Mater. 2012, 239-240, 152-159.

(22) Rafatullah, M.; Sulaiman, O.; Hashim, R.; Ahmad, A. Adsorption of Methylene Blue on Low-Cost Adsorbents: A Review. J. Hazard. Mater. 2010, 177, 70-80.

(23) de Paula, F. G. F.; de Castro, M. C. M.; Ortega, P. F. R.; Blanco, C.; Lavall, R. L.; Santamaría, R. High Value Activated Carbons from Waste Polystyrene Foams. Microporous Mesoporous Mater. 2018, 267, 181-184.

(24) Chen, G. Z. Supercapacitor and Supercapattery as Emerging Electrochemical Energy Stores. Inter. Mater. Rev. 2017, 62, 173-202. 
(25) Roldan, S.; Barreda, D.; Granda, M.; Menendez, R.; Santamaria, R.; Blanco, C. An Approach to Classification and Capacitance Expressions in Electrochemical Capacitors Technology. Phys. Chem. Chem. Phys. 2015, 17, 1084-1092.

(26) Roldán, S.; Granda, M.; Menéndez, R.; Santamaría, R.; Blanco, C. Supercapacitor Modified with Methylene Blue as Redox Active Electrolyte. Electrochim. Acta 2012, 83, 241-246.

(27) Ortega, P. F. R.; Trigueiro, J. P. C.; Santos, M. R.; Denadai, A. M. L.; Oliveira, L. C. A.; Teixeira, A. P. C.; Silva, G. G.; Lavall, R. L. Thermodynamic Study of Methylene Blue Adsorption on Carbon Nanotubes Using Isothermal Titration Calorimetry: A Simple and Rigorous Approach. J. Chem. Eng. Data 2017, 62, 729-737.

(28) Li, Y.; Du, Q.; Liu, T.; Peng, X.; Wang, J.; Sun, J.; Wang, Y.; Wu, S.; Wang, Z.; Xia, Y.; Xia, L. Comparative Study of Methylene Blue Dye Adsorption onto Activated Carbon, Graphene Oxide, and Carbon Nanotubes. Chem. Eng. Res. Des. 2013, 91, 361368.

(29) Chagovets, V. V.; Kosevich, M. V.; Stepanian, S. G.; Boryak, O. A.; Shelkovsky, V. S.; Orlov, V. V.; Leontiev, V. S.; Pokrovskiy, V. A.; Adamowicz, L.; Karachevtsev, V. A. Noncovalent Interaction of Methylene Blue with Carbon Nanotubes: Theoretical and Mass Spectrometry Characterization. J. Phys. Chem. C 2012, 116, 20579-20590.

(30) Yao, H.; Li, N.; Xu, S.; Xu, J.-Z.; Zhu, J.-J.; Chen, H.-Y. Electrochemical Study of a New Methylene Blue/Silicon Oxide Nanocomposition Mediator and its Application for Stable Biosensor of Hydrogen Peroxide. Biosens. Bioelectron. 2005, 21, 372-377.

(31) Yan, Y.; Zhang, M.; Gong, K.; Su, L.; Guo, Z.; Mao, L. Adsorption of Methylene Blue Dye onto Carbon Nanotubes: A Route to an Electrochemically Functional Nanostructure and its Layer-by-Layer Assembled Nanocomposite. Chem. Mater. 2005, 17, 3457-3463.

(32) Barreda, D.; Pérez-Mas, A. M.; Silvestre-Albero, A.; Casco, M. E.; Rudić, S.; Herdes, C.; Müller, E. A.; Blanco, C.; Santamaria, R.; Silvestre-Albero, J.; RodríguezReinoso, F. Unusual Flexibility of Mesophase Pitch-Derived Carbon Materials: An Approach to the Synthesis of Graphene. Carbon 2017, 115, 539-545.

(33) Borenstein, A.; Hershkovitz, S.; Oz, A.; Luski, S.; Tsur, Y.; Aurbach, D. Use of 1,10-Phenanthroline as an Additive for High-Performance Supercapacitors. J. Phys. Chem. C 2015, 119, 12165-12173.

(34) Tian, Y.; Xue, R.; Zhou, X.; Liu, Z.; Huang, L. Double Layer Capacitor Based on Active Carbon and its Improved Capacitive Properties using Redox Additive Electrolyte of Anthraquinonedisulphonate. Electrochim. Acta 2015, 152, 135-139.

(35) Ma, G.; Feng, E.; Sun, K.; Peng, H.; Li, J.; Lei, Z. A Novel and High-Effective Redox-Mediated Gel Polymer Electrolyte for Supercapacitor. Electrochim. Acta 2014, 135, 461-466. 
(36) Roldán, S.; González, Z.; Blanco, C.; Granda, M.; Menéndez, R.; Santamaría, R. Redox-Active Electrolyte for Carbon Nanotube-Based Electric Double Layer Capacitors. Electrochim. Acta 2011, 56, 3401-3405.

(37) Zhang, T.; Oyama, T.; Aoshima, A.; Hidaka, H.; Zhao, J.; Serpone, N. Photooxidative N-Demethylation of Methylene Blue in Aqueous TiO2 Dispersions under UV Irradiation. J. Photochem. Photobiol. A 2001, 140, 163-172.

(38) Rauf, M. A.; Meetani, M. A.; Khaleel, A.; Ahmed, A. Photocatalytic Degradation of Methylene Blue using a Mixed Catalyst and Product Analysis by LC/MS. Chem. Eng. J. 2010, 157, 373-378. 